\title{
Induced-fit motion of a lid loop involved in catalysis in alginate lyase A1-III.
}

\section{$\operatorname{AUTHOR}(\mathrm{S})$ :}

Mikami, Bunzo; Ban, Mizuho; Suzuki, Sachiko; Yoon, HyeJin; Miyake, Osamu; Yamasaki, Masayuki; Ogura, Kohei; Maruyama, Yukie; Hashimoto, Wataru; Murata, Kousaku

\section{CITATION:}

Mikami, Bunzo ...[et al]. Induced-fit motion of a lid loop involved in catalysis in alginate lyase A1-III.. Acta crystallographica. Section D, Biological crystallography 2012, 68(Part 9): $1207-1216$

\section{ISSUE DATE:}

2012-09

URL:

http://hdl.handle.net/2433/161048

\section{RIGHT:}

(C) 2012 International Union of Crystallography

Printed in Singapore 
Acta Crystallographica Section D

Biological Crystallography

ISSN 0907-4449

Bunzo Mikami, ${ }^{\mathrm{a}} \neq$ Mizuho

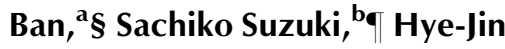
Yoon, ${ }^{a} \neq \neq$ Osamu Miyake, ${ }^{b} \S \S$ Masayuki Yamasaki, aq Kohei

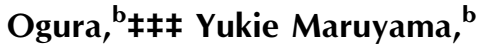
Wataru Hashimoto ${ }^{b}$ and Kousaku Murata ${ }^{\mathbf{b}} \neq$

aLaboratory of Applied Structural Biology, Department of Applied Life Science, Graduate School of Agriculture, Kyoto University, Gokasho, Uji, Kyoto 611-0011, Japan, and baboratory of Basic and Applied Molecular Biotechnology, Department of Food Science, Graduate School of Agriculture, Kyoto University, Gokasho, Uji, Kyoto 611-0011, Japan

₹ BM and KM contributed equally to this paper. $\S$ Present address: Department of Food and Nutrition, Sanyo Gakuen Junior College, 1-14-1 Hirai, Naka-ku, Okayama 703-8501, Japan.

- Present address: Research Institute, Gekkeikan Sake Company Ltd, 300 Katahara-cho, Fushimi-ku, Kyoto 612-8361, Japan. \#‡ Present address: School of Chemistry, Seoul National University, Seoul 151-742, Republic of Korea.

$\S \S$ Present address: Division of Food Nutrition, Kyoto Junior College, 3370 Nishi-Kotanigaoka, Fukuchiyama, Kyoto 620-0886, Japan. ฯ Present address: Young Researcher Development Centre (The Hakubi Centre), Institute for Frontier Medical Sciences, Kyoto University, Sakyo-ku, Kyoto 606-8397, Japan.

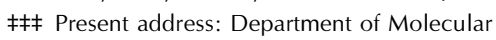
Infectiology, Graduate School of Medicine, Chiba University, 1-8-1 Inohana, Chuo-ku, Chiba 260-0856, Japan.

Correspondence e-mail: mikami@kais.kyoto-u.ac.jp

(C) 2012 International Union of Crystallography Printed in Singapore - all rights reserved

\section{Induced-fit motion of a lid loop involved in catalysis in alginate lyase A1-III}

The structures of two mutants (H192A and Y246F) of a mannuronate-specific alginate lyase, A1-III, from Sphingomonas species A1 complexed with a tetrasaccharide substrate [4-deoxy-L-erythro-hex-4-ene-pyranosyluronate-(mannuronate) ${ }_{2}$ mannuronic acid] were determined by X-ray crystallography at around $2.2 \AA$ resolution together with the apo form of the H192A mutant. The final models of the complex forms, which comprised two monomers (of 353 amino-acid residues each), 268-287 water molecules and two tetrasaccharide substrates, had $R$ factors of around 0.17. A large conformational change occurred in the position of the lid loop (residues 64-85) in holo H192A and Y246F compared with that in apo H192A. The lid loop migrated about $14 \AA$ from an open form to a closed form to interact with the bound tetrasaccharide and a catalytic residue. The tetrasaccharide was bound in the active cleft at subsites -3 to +1 as a substrate form in which the glycosidic linkage to be cleaved existed between subsites -1 and +1 . In particular, the $\mathrm{O}^{\eta}$ atom of Tyr68 in the closed lid loop forms a hydrogen bond to the side chain of a presumed catalytic residue, $\mathrm{O}^{\eta}$ of Tyr246, which acts both as an acid and a base catalyst in a syn mechanism.

\section{Introduction}

The degradation of acid polysaccharides such as alginate proceeds by a lyase reaction, which produces double-bonded sugars at the nonreducing end of the product. Among the 21 families (PL-1 to PL-21) of polysaccharide lyases classified in the CAZY database (Carbohydrate Active Enzymes database; http://www.cazy.org/; Cantarel et al., 2009), the structures of enzymes from 19 families have been deternined (Garron \& Cygler, 2010; Lombard et al., 2010). In order to elucidate the mechanism by which these enzymes degrade acid polysaccharides, the structures of complexes of many lyases with ligands including the substrates and/or products of these lyases have been reported (Garron \& Cygler, 2010; Lombard et al., 2010; Ochiai et al., 2010; Shaya et al., 2010). It has been reported that the Tyr, His and Asn triad is conserved and plays an important role in the catalysis of polysaccharide lyases in the PL-5 (Yoon et al., 2001), PL-7 (Ogura et al., 2008; Yamasaki et al., 2005; Osawa et al., 2005) and PL-8 (Féthière et al., 1999; Lunin et al., 2004; Huang et al., 2001; Li \& Jedrzejas, 2001; Mello et al., 2002; Nukui et al., 2003; Rigden \& Jedrzejas, 2003) families. There is a structural similarity between the catalytic domains of PL-5 and PL-8. In alginate lyase (PL-5; Yoon et al., 2001), chondroitin AC lyase (PL-8; Féthière et al., 1999; Lunin et al., 2004; Huang et al., 2001) and xanthan lyase
Received 2 December 2011 Accepted 31 May 2012

PDB References: A1-III, H192 mutant, apo, 4e1y; $\mathrm{H} 192$ mutant, complexed with alginate tetrasaccharide, $4 \mathrm{f} 10$; Y246F mutant, complexed with alginate tetrasaccharide, $4 \mathrm{f} 13$. 
(PL-8; Maruyama et al., 2005, 2007) the catalytic residue which accepts a hydrogen from $\mathrm{C} 5$ at the +1 sugar subsite and donates hydrogen to the glycosidic $\mathrm{O}$ atom to be cleaved has been reported to be a Tyr residue. In contrast, His is the proton acceptor and Tyr is the proton donor in hyaluronate lyase (PL-8; Ponnuraj \& Jedrzejas, 2000; Li et al., 2001; Jedrzejas et al., 2002; Li \& Jedrzejas, 2001; Mello et al., 2002; Nukui et al., 2003; Rigden \& Jedrzejas, 2003; Rigden et al., 2006). However, recent analysis of another PL-8 hyaluronate lyase complexed with a disaccharide suggested that Tyr is involved in proton abstraction from the substrate (Elmabrouk et al., 2011).

The alginate lyase A1-III is a $\beta$-D-mannuronosyl linkagespecific (M-M-specific) enzyme that acts on alginate tetrasaccharide as the minimum substrate and produces disaccharides and trisaccharides from alginate (Murata et al., 1993; Yonemoto et al., 1993). The structure of an A1-III crystal at $1.78 \AA$ resolution was reported as the first example of a family PL-5 enzyme (Yoon et al., 1999). Based on the structure of A1-III complexed with a trisaccharide product, it was proposed that Tyr246 is a catalytic residue that is responsible for both the abstraction and the donation of hydrogen (Yoon et al., 2001). However, the complex structure was insufficient in two respects. Firstly, the enzyme was not in an active form, having a fixed open lid-loop region (residues 64-85) caused by crystallographic interactions. Secondly, the product sugars did not bind to cover the subsites on either side of the catalytic residue (subsites -3 to -1 ). It is important to overcome crystallographic artifacts such as symmetry interactions and the effects of freezing in order to elucidate the conformational changes and complex formation in the enzymatic process. An accurate determination of the structure of the mutant enzyme-substrate complex without crystallographic artifacts is necessary in order to elucidate the catalytic residue (Dunlop et al., 2005; Skrzypczak-Jankun et al., 2006).

In this paper, we describe the crystal structures of mutant alginate lyases (H192A and Y246F) complexed with tetrasaccharide substrates at around $2.2 \AA$ resolution. We thus determined a new crystal form of the enzyme in which the lidloop region can move from an open to a closed form by an induced-fit motion. For the first time, we were able to determine the structure of a sugar bound at subsite +1 in the closed lid-loop form. We used crystals enclosed in capillaries in order to avoid the effects of freezing.

\section{Materials and methods}

\subsection{Preparation of mutant enzymes}

A1-III mutants with mutations of the amino-acid residues in the active site (Y246F, H192A, G60A, R67A, Y68F and Y80F) were prepared by site-directed mutagenesis with plasmid pET3a-A1-III (Yoon et al., 2000) as a template using the QuikChange Site-Directed Mutagenesis kit (Stratagene, La Jolla, California, USA) according to the manufacturer's instructions. The mutated genes were amplified by PCR. Escherichia coli strain BL21(DE3)pLysS (Novagen Inc.,
Madison, Wisconsin, USA) was used as a host for expression of the mutated genes. The mutations were confirmed by analysis of the nucleotide sequences of the mutated genes. The transformants of E. coli BL21(DE3)pLysS with the plasmids containing each mutated gene produced large volumes of mutant enzymes in soluble form. Purification and activity assays of the mutant enzymes were performed as described previously (Yoon et al., 2000).

\subsection{Crystallization and structure analysis}

Using numerous crystallization screens, we obtained several crystal forms of the H192A and Y246F mutants in space groups including that of the original A1-III structure $(C 2$; Yoon et al., 1999, 2001), $P 2_{1}$ and $P 2_{1} 2_{1} 2_{1}$. Among these crystal forms, only the $P 2_{1} 2_{1} 2_{1}$ crystal had a mobile lid-loop region without symmetry-packing interactions. The $P 2_{1} 2_{1} 2_{1}$ crystals of these mutants were obtained by the hanging-drop vapourdiffusion method against 24\%(w/v) PEG 4000, $0.3 \mathrm{M}$ ammonium acetate, $0.1 M$ sodium citrate $\mathrm{pH} 5.5$ at $293 \mathrm{~K}$ with a protein concentration of around $10 \mathrm{mg} \mathrm{ml}^{-1}$. Prismatic crystals appeared in a month. Holoenzyme crystals were obtained by soaking these crystals with $12.5-50 \mathrm{~m} M$ alginate tetrasaccharide at $293 \mathrm{~K}$ for $30 \mathrm{~min}$. In order to avoid the release of substrate from the enzyme during freezing, data collection was carried out by the capillary method at $293 \mathrm{~K}$. The crystals and a drop of the mother liquor were placed in a glass capillary sealed with dental wax at both ends. Diffraction data were collected from apo and holo H192A crystals on an in-house multi-wire detector (Hi-Star; Bruker, Karlsruhe, Germany) with $\mathrm{Cu} K \alpha$ radiation generated by a rotating-anode generator (M18XHF; MacScience, Tokyo, Japan) at $293 \mathrm{~K}$. The raw data images were processed using the SADIE and SAINT software packages (Bruker). The diffraction data of holo Y246F crystals were collected on the BL38B1 beamline of SPring- 8 by the capillary method at $298 \mathrm{~K}$ using a CCD detector (Quantum 4; ADSC, Poway, California, USA) at a wavelength of $1.0 \AA$. The collected images were processed with the $H K L-2000$ package (Otwinowski \& Minor, 1997).

The structures of the H192A and Y246F mutants were determined by molecular replacement with the CNS_SOLVE package (Brünger et al., 1998) using wild-type A1-III (PDB entry 1qaz; Yoon et al., 1999) as a search model. The final refinement of the structures was carried out by PHENIX (Adams et al., 2010) using noncrystallographic symmetry restraints. The models were rebuilt using TURBO-FRODO (CNRS, France) and Coot (Emsley et al., 2010). The stereochemical quality of the final models was assessed using PROCHECK (Laskowski et al., 1993) and WHATCHECK (Hooft et al., 1996). The puckering parameters (Cremer \& Pople, 1975) of the bound alginate tetrasaccharides were calculated using the PLATON package (Spek, 2003). The subsite numbers of the bound tetrasaccharides were designated as $-3,-2,-1$ and +1 from the reducing end based on the rule of Davies et al. (1997). The accessible surface area was calculated by the program NACCESS (Hubbard \& Thornton, 1993). The CCP4 package (Winn et al., 2011) was used for the 
Table 1

Kinetic parameters of the mutant enzymes.

\begin{tabular}{lllcc}
\hline Enzyme & $\begin{array}{l}K_{\mathrm{m}} \\
\left(\mathrm{mg} \mathrm{ml}^{-1}\right)\end{array}$ & $\begin{array}{l}V_{\max } \\
\left(\Delta A_{235 \mathrm{~nm}} \mathrm{~min}^{-1} \mathrm{mg}^{-1}\right)\end{array}$ & $\begin{array}{l}V_{\max } \\
(\%)\end{array}$ & $\begin{array}{l}\text { Relative } \\
V_{\max } / K_{\mathrm{m}} \\
(\%)\end{array}$ \\
\hline Wild type & 0.041 & 72.7 & 100 & 100 \\
H192A & 0.027 & 0.0030 & 0.0033 & 0.0050 \\
Y246F & 0.079 & 0.0024 & 0.011 & 0.0057 \\
G60A & 0.056 & 21.8 & 80.0 & 58.6 \\
M62P, intact & 0.050 & 32.0 & 44.0 & 42.0 \\
M62P, nicked & 0.029 & 0.011 & 0.015 & 0.020 \\
R67A & 0.169 & 22.5 & 31.0 & 7.5 \\
Y68F & 0.177 & 16.0 & 22.0 & 5.1 \\
Y80F & 0.038 & 35.6 & 49.0 & 52.9 \\
\hline
\end{tabular}

manipulation of data and coordinates. The figures were drawn using PyMOL (v.1.19; Schrödinger LLC).

\subsection{Preparation of alginate tetrasaccharide}

Alginate tetrasaccharide was prepared from a digest of alginate with A1-III by gel filtration as described previously (Yoon et al., 2001).

\subsection{Amino-acid sequencing}

The N-terminal protein sequence of mutant alginate lyase A1-III (M62P) was analyzed by Edman degradation in a pulsed liquid-phase protein sequencer (Procise 492; Applied
Biosystems) after blotting the SDS gel onto a polyvinylidene membrane.

\subsection{Alignment of amino-acid sequences}

The multiple alignment of the amino-acid sequences of mannuronate-specific alginate lyases from Pseudomonas syringae (Preston et al., 2000), P. fluorescens (Gimmestad et al., 2003), P. aeruginosa (Boyd et al., 1993), Cobetia marina (Swiss-Prot Q9ZNB7) and Azotobacter chroococcum (Peciña et al., 1999) was performed using ClustalW (Thompson et al., 1994).

\section{Results and discussion}

\subsection{Mutation of residues in the active site and lid loop of A1-III}

Both the mutant of the assumed catalytic residue, Y246F, and that of the adjacent residue, H192A, showed large decreases in $V_{\max }$ values of the order of $10^{-5}$ compared with the wild-type enzyme (Table 1). The mutants of the residues on the lid loop (residues 57-90), G60A, M62P, R67A, Y68F and $\mathrm{Y} 80 \mathrm{~F}$, showed $V_{\max }$ values that were $22-80 \%$ lower than that of the wild-type enzyme. After Y246F and H192A, Y68F showed the largest effect on the activity, decreasing the $V_{\max } / K_{\mathrm{m}}$ value to $5.1 \%$ of the value for the wild-type enzyme. Two components of M62P, intact M62P and nicked M62P, were found during purification of the mutant enzyme. Analysis of the $\mathrm{N}$-terminal amino acids of the fragments of the nicked form indicated two sequences derived from the $\mathrm{N}$-terminus ( ${ }^{1}$ MHPFD ... ) and from the cleaved site $\left({ }^{67}\right.$ RYLSE ...), suggesting that amino acids in the vicinity of Arg66 are deleted in the nicked form owing to proteolysis during purification. The large decrease in the activity of the nicked M62P (of the order of $10^{-4}$ ) suggests the importance of the lid loop for enzymatic activity.

\subsection{Quality of the final models}

In the preliminary crystallization screening several crystal forms were obtained, but most of them had a fixed open loop owing to symmetry interactions in the crystal packing. Even in the present $P 2_{1} 2_{1} 2_{1}$ crystals the open lid loop in one of the two molecules in the asymmetric unit makes weak interactions with an adjacent symmetry molecule. The other problem arose owing to crystal cooling, which resulted in dissociation of the substrate from the molecule, as described previously (Yoon et al., 2001). In the present work, therefore, we collected crystallographic data by the capillary method without cooling. The refinement of the apo H192A, holo H192A and holo Y246F structures was carried out 


\section{research papers}

Table 2

Data-collection and refinement statistics for mutant A1-III.

Values in parentheses are for the highest resolution shell.

\begin{tabular}{|c|c|c|c|}
\hline & Apo H192A & H192A-tetrasaccharide & Y246F-tetrasaccharide \\
\hline Substrate $(\mathrm{m} M)$ & 0 & 50 & 12.5 \\
\hline \multicolumn{4}{|l|}{ Diffraction data } \\
\hline X-ray source & In-house & In-house & BL38B1, SPring-8 \\
\hline Wavelength $(\AA)$ & 1.54 & 1.54 & 1.00 \\
\hline Detector & Hi-Star multiwire & Hi-Star multiwire & Quantum-4 CCD \\
\hline Space group & $P 2_{1} 2_{1} 2_{1}$ & $P 2_{1} 2_{1} 2_{1}$ & $P 2_{1} 2_{1} 2_{1}$ \\
\hline Unit-cell parameters $(\AA)$ & $\begin{array}{c}a=65.44, b=76.99 \\
\quad c=143.52\end{array}$ & $\begin{array}{c}a=65.43, b=77.60 \\
\quad c=145.75\end{array}$ & $\begin{array}{c}a=65.57, b=77.56 \\
\quad c=145.68\end{array}$ \\
\hline Resolution limits $(\AA ̊)$ & $40.6-2.10(2.22-2.10)$ & $41.2-2.20(2.28-2.20)$ & $48.7-2.20(2.24-2.20)$ \\
\hline Measured reflections & 186118 (14476) & 213009 (10552) & $196763(9785)$ \\
\hline$\langle I / \sigma(I)\rangle$ & $12.1(2.6)$ & $13.2(2.8)$ & $16.7(3.0)$ \\
\hline Unique reflections & $41806(6213)$ & $38230(3686)$ & $36529(3116)$ \\
\hline Completeness (\%) & $97.0(93.2)$ & $99.4(97.5)$ & $96.2(95.9)$ \\
\hline$R_{\text {sym }}$ or $R_{\text {merge }}(\%)$ & $6.2(29.8)$ & $8.9(36.7)$ & $9.8(48.4)$ \\
\hline Wilson $B\left(\AA^{2}\right)$ & 20.8 & 17.2 & 25.7 \\
\hline \multicolumn{4}{|l|}{ Refinement } \\
\hline Resolution range $(\AA)$ & $40.6-2.10(2.16-2.10)$ & $41.2-2.20(2.26-2.20)$ & $48.7-2.21(2.27-2.21)$ \\
\hline Reflections used & $41806(2601)$ & $38167(2630)$ & $36472(2603)$ \\
\hline Completeness (\%) & $97.0(92.4)$ & $99.5(97.2)$ & $95.9(91.0)$ \\
\hline Residues/waters & $706 / 287$ & $693 / 286$ & $699 / 270$ \\
\hline Disordered residues & 14 & 11 & 12 \\
\hline Tetrasaccharide & - & $\Delta \mathrm{M}-\mathrm{G}-\mathrm{M}-\mathrm{M} / \mathrm{G}-\mathrm{M}$ & $\Delta \mathrm{M}-\mathrm{M}-\mathrm{M}-\mathrm{M} / \mathrm{M}-\mathrm{M}$ \\
\hline Sugar-occupied sites & - & +1 to $-3 /-1$ to -2 & +1 to $-3 /-1$ to -2 \\
\hline Lid-loop position $(A / B)$ & Open/open & Closed/not visible & Closed/not visible \\
\hline Average $B$ factor $\left(\AA^{2}\right)$ & 29.5 & 25.2 & 30.8 \\
\hline Bond-length r.m.s.d. $(\AA)$ & 0.012 & 0.013 & 0.010 \\
\hline Bond-angle r.m.s.d. $\left({ }^{\circ}\right)$ & 1.33 & 1.37 & 1.31 \\
\hline$R$ factor $(\%)$ & $16.3(28.7)$ & $19.4(31.8)$ & $17.7(24.8)$ \\
\hline$R_{\text {free }}(\%)$ & $20.6(36.7)$ & $23.9(34.8)$ & $21.4(32.7)$ \\
\hline
\end{tabular}

by PHENIX, as shown in Table 2. The final holo-form models contained $2 \times$ 353 amino-acid residues, 270-286 water molecules and two alginate tetrasaccharides (Fig. 1). There are 11-14 disordered residues in the structures. The invisible parts of molecule $B$ in the holo-form models around residues 6677 and two sugars were deleted from the final model. The $R$ factors $\left(R_{\text {free }}\right)$ for the data to 2.1-2.2 $\AA$ resolution were 0.163 (0.206), 0.194 (0.239) and 0.177 (0.214) for apo H192A, holo H192A and holo Y246F, respectively. In the Ramachandran plots (Ramachandran \& Sasisekharan, 1968; Laskowski et al., 1993), 98.8, 99.7 and $99.7 \%$ of nonglycine residues were in the most favoured and additionally allowed regions, respectively. The absolute coordinate errors estimated from Luzatti plots (Luzzati, 1952) were $0.20-0.23 \AA$, respectively. The r.m.s. distances of the two molecules in an asymmetric unit were 0.31 , 0.35 and $0.31 \AA$ for 343,340 and $333 \mathrm{C}^{\alpha}$ atoms for apo H192A, holo H192A and holo Y246F, respectively. In the structures of holo H192A and Y246F one molecule (molecule $A$ ) has a closed lid loop, while the other (molecule $B$ ) has an invisible lid loop that may be alternately opened and closed. Because the electron-density map of the lid loop and the bound sugar in molecule $B$ is poor owing to low occupancy and high $B$ factors, we used the structures of molecule $A$ of holo H192A and $\mathrm{Y} 246 \mathrm{~F}$ in the following analysis of enzyme-substrate interactions (Fig. 1).

\subsection{Overall structure}

A large conformational change of the lid loop (residues 6485) was found between the structures of the apo (H192A) and the holo forms (H192A and Y246F), as shown in Figs. 1 and 2. The secondary-structure elements $(\mathrm{H} 1-\mathrm{H} 12)$ were defined as described in Yoon et al. (1999). The open lid loop that protruded into the solvent moved to the closed form by bending at the middle of L2 (the loop connecting $\mathrm{H} 2$ and $\mathrm{H} 3$; residues 44-79) and part of $\mathrm{H} 3$ (residues 80-105), with the result that the active-site cleft was covered (Figs. 1 and 2). The r.m.s. distance between apo and holo $\mathrm{H} 192 \mathrm{~A}$ was $0.62 \AA$ for $353 \mathrm{C}^{\alpha}$ atoms of molecule $A$, while that between holo H192A and holo F246Y was $0.17 \AA$, suggesting that the difference was caused by the conformational change of the lid loop. Fig. 3( $a)$ shows $B$-factor plots for apo and holo H192A (molecule $A$ ) along the sequence together with the r.m.s. distance between the two molecules. The average $B$ factor of the lid-loop region (residues $64-85)$ is high in the apoenzyme $\left(47.4 \AA^{2}\right.$ ), but becomes lower in holo H192A $\left(23.1 \AA^{2}\right)$ in accord with the
Lid-loop motion in the active site of A1-III. The open (red) and closed (green) lid loops are shown together with the bound tetrasaccharide (circles) on the molecular surface after superposition of apo and holo H192A. The sugar residues at subsites +1 to -3 are shown in magenta and red, alternately. 


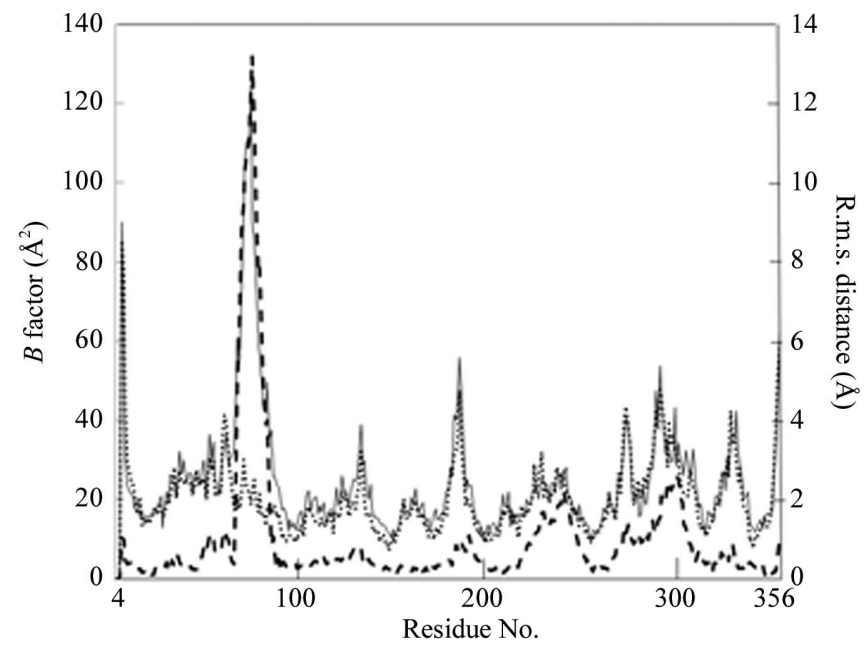

(a)

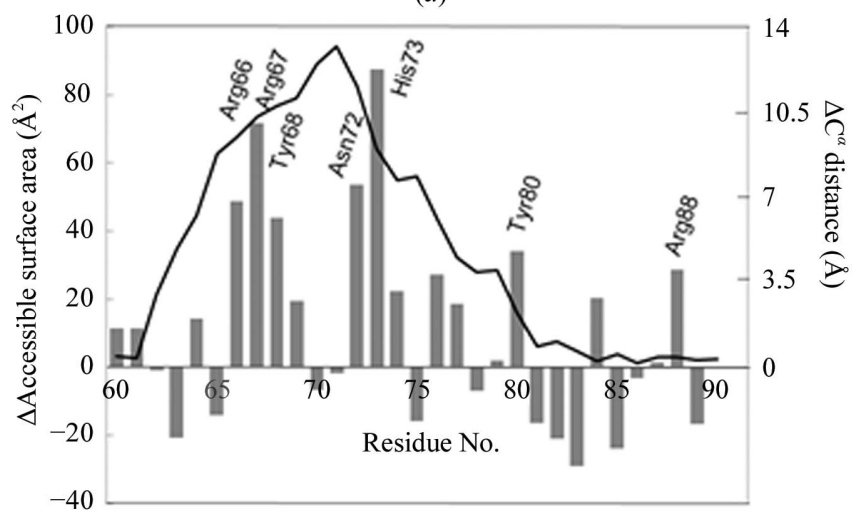

(b)
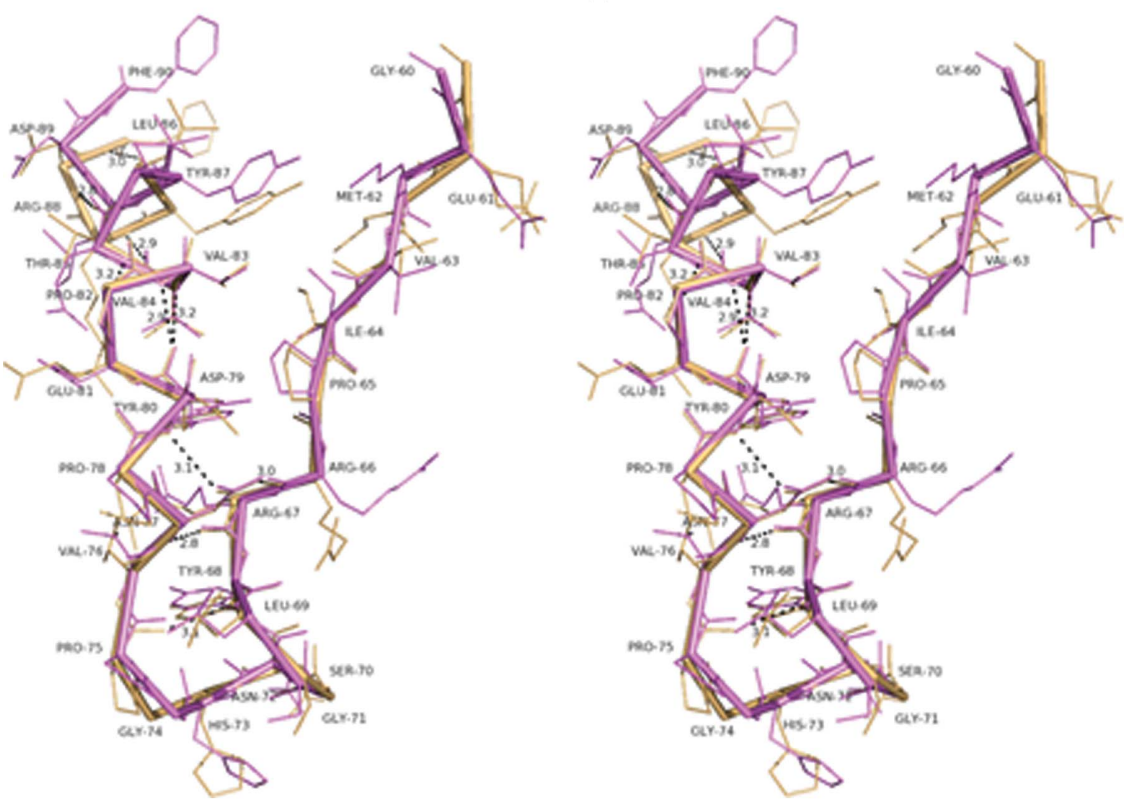

(c)

Figure 3

(a) The average $B$ factors and the r.m.s. distance between apo and holo H192A along the amino-acid sequence. The average $B$ factors of apo and holo H192A are indicated by straight and dotted lines, respectively. The r.m.s. distance of $\mathrm{C}^{\alpha}$ atoms is indicated by a thick dashed line. The lid-loop region (residues 64-85) has the highest $B$ factor in the apo form and the largest r.m.s. distance. (b) The r.m.s. distance and the change in accessible surface area of residues on the lid loop of $\mathrm{H} 192 \mathrm{~A}$ are represented by a line and by bars, respectively. (c) Superposition of the open (magenta) and closed (yellow) lid loops of H192A after superposition of $22 \mathrm{C}^{\alpha}$ atoms in the lid loop (residues 64-85) (stereoview). peak in the r.m.s. distance plot. The maximum movement increases in residues 73-75, reaching $13.4 \AA$ between $\mathrm{C}^{\alpha}$ atoms at Gly74.

The two molecules (molecules $A$ and $B$ ) in the asymmetric unit behaved differently in the holo structures. Molecule $A$ has a completely closed lid loop, but molecule $B$ has invisible lid loops (Fig. 1). The two molecules have different crystal packings. The open lid loop of molecule $B$ in apo H192A makes interactions with the adjacent molecule $B$ including three hydrogen bonds (Asp79 $\mathrm{O}^{\delta 2} \ldots \# A r g 276 \mathrm{~N}^{\eta 1}, 2.8 \AA$; Pro78 O ...Wat...\#Glu229 N, 2.7 and $2.9 \AA$ ) and two C-C contacts (Pro82 $\mathrm{C}^{\gamma} \ldots \# \mathrm{Glu} 229 \mathrm{C}^{\beta}$, $3.6 \AA$; Pro78 C $\mathrm{C}^{\beta}$. . \#Asn228 $\mathrm{C}^{\alpha}, 4.0 \AA$ A). Thus, the lid loop of molecule $B$ is fixed in an open position. In contrast, the open lid loops of molecule $A$ in holo H192A and holo Y246F make weak interactions with molecule $B$ in the same asymmetric unit, including a few van der Waals contacts with $\mathrm{C}-\mathrm{C}$ distances less than $4.4 \AA$ (Pro75A ‥Asp37B, Pro78 $A$ ‥Ala41B, Pro78A..Val336B, Pro82A... Val336B, Thr85 $A \cdots$ Lys309B and Glu81 $A$ ..Thr335B). The binding of tetrasaccharide results in complete and partial lid-loop closure in molecules $A$ and $B$, respectively, in the capillary crystals. However, crystal cooling resulted in the complete opening of both lid loops and the release of the bound tetrasaccharide, possibly owing to shrinkage of the crystal lattice and the resulting increase in the above interactions, as described for other proteins (Dunlop et al., 2005; Skrzypczak-Jankun et al., 2006). In addition to cell shrinkage, cooling may change the $\mathrm{pH}$ of the solvent in the crystal. Moreover, cryoprotectants such as glycerol and MPD are potent inhibitors of sugarrelated enzymes such as alginate lyase (Tsitsanou et al., 1999).

\subsection{Lid-loop motion}

Superposition of the open and closed lid loops suggests that the conformational change results in near-rigid-body motion (Fig. 3c). The r.m.s. deviation of the $22 \mathrm{C}^{\alpha}$ pairs (residues 64-85) of the open and closed lid loops is only $0.46 \AA$. At the N-terminus of the mobile lid loop, Ile64 makes the hinge by changing its main-chain dihedral angles from $(\varphi, \psi)=\left(-98^{\circ}, 116^{\circ}\right)$ in the open form to $\left(-137^{\circ}, 126^{\circ}\right)$ and $\left(-132^{\circ}\right.$, $\left.128^{\circ}\right)$ in the $\mathrm{H} 192 \mathrm{~A}$ and $\mathrm{Y} 246 \mathrm{~F}$ closed forms, 


\section{research papers}

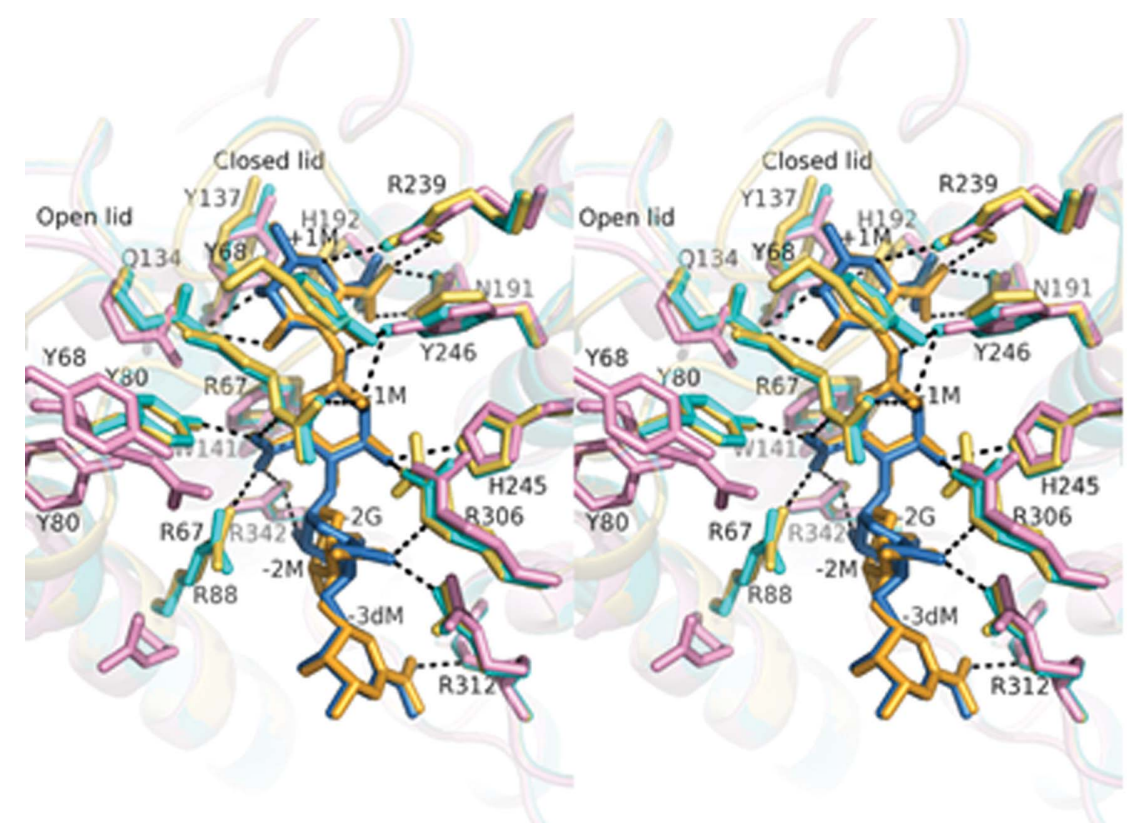

(a)

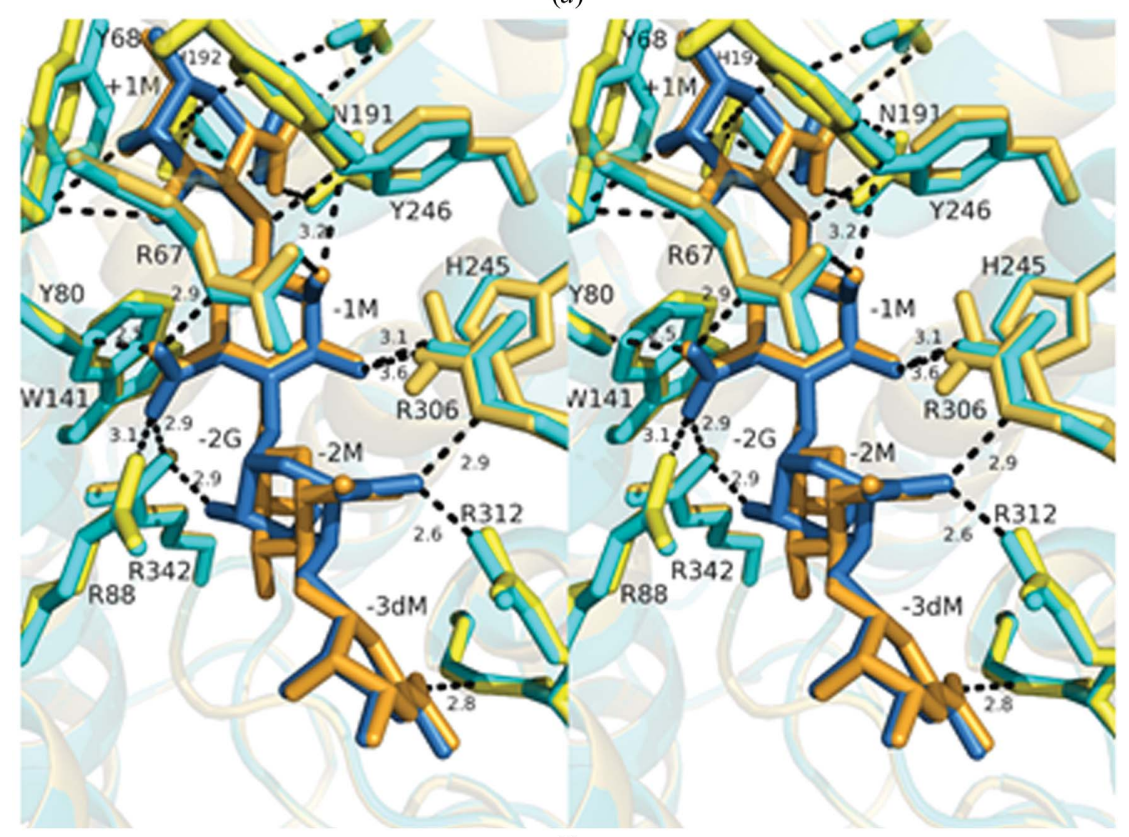

(b)

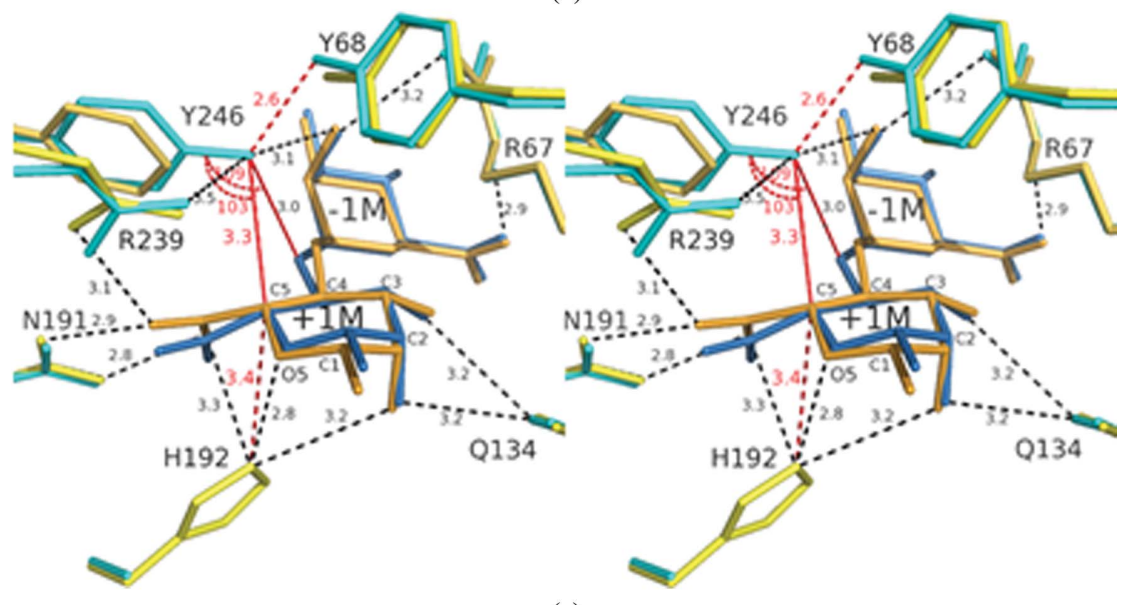

(c) respectively. In contrast, at the $\mathrm{C}$-terminus of the lid loop the movement ended gradually in the middle of the $\mathrm{H} 3$ helix through small changes in dihedral angles from residues 82 to 85 , resulting in an approximately $19^{\circ}$ bend of $\mathrm{H} 3$ (Fig. 2).

The open-closed movement of the lid loop decreases the accessible surface area of $582 \AA^{2}$ by covering the active-site cleft. In particular, the side chains of Arg66, Arg67, Tyr68, Asn72, His73, Tyr80 and Arg88 are buried in the closed lid loop (Fig. 3b). Most of these residues are important for interaction with the substrate. The side chains of Tyr68 and Asn72 make three nascent hydrogen bonds to residues in the cleft of holo H192A (Tyr68 O ${ }^{\eta}$. . Tyr246 O ${ }^{\eta}, 2.6 \AA$; Asn72 O ‥Arg239 N ${ }^{\eta 2}, 2.7 \AA$; Asn72 O... $\operatorname{Arg} 239 \mathrm{~N}^{\varepsilon}, 3.3 \AA$ ). Because the closed lid loop completely covers the active-site cleft, it should be open during the release of the product and the incorporation of the next substrate (Fig. 2). The motion of the lid loop is classified as a fragment motion of the hinge mechanism (Gerstein \& Krebs, 1998). The fragment region of 22 residues including part of H3 is larger than the usual $\omega$-loop with an open and closed motion, as represented by triose phosphate isomerase (Noble et al., 1993).

\subsection{Structure of bound alginate tetrasaccharide}

From the density of the bound tetrasaccharide, it is suggested that the H192A and Y246F mutants bind different alginate tetrasaccharides in their active sites (Figs. $4 a$ and $4 b$ ). In the Y246F holo form, the four sugar residues were identified as $\beta$-mannuronate $(\mathrm{M})$ at subsites between +1 and -2 and a double-bonded sugar $(\Delta \mathrm{M})$ at subsite -3 , while the $\beta$-mannuronate at subsite -2 was replaced by an $\alpha$-guluronate (G) in the case of the H192A holo form.

\section{Figure 4}

Interaction of the tetrasaccharide with protein residues in $\mathrm{H} 192 \mathrm{~A}$ and $\mathrm{Y} 246 \mathrm{~F}$ (stereoview). (a) The structures of apo H192A, holo H192A and holo Y246F are shown in pink, cyan and yellow, respectively. Estimated hydrogen bonds are shown as broken lines. (b) Close-up view around the -1 and -2 sites after superposition of H192A (cyan) and Y246F (yellow). (c) Close-up view around the +1 sites after superposition of H192A (cyan) and Y246F (yellow). The Tyr246 O $\mathrm{O}^{\eta} \ldots \mathrm{C} 5$, His $192 \mathrm{~N}^{\varepsilon 2} \ldots$ $\mathrm{C} 5$ and Tyr246 $\mathrm{O}^{\eta} \ldots$ Tyr68 $\mathrm{O}^{\eta}$ distances are shown in red. 
Because the alginate tetrasaccharide used in the present experiment is a mixture mainly consisting of mannuronate, the substrate specificity of these two mutants is likely to be slightly different. Table 3 shows the sugarpuckering parameters (Cremer \& Pople, $1975)$ and $B$ factors of the bound sugar residues. The outer sugars (subsites +1 and -3 ) have higher $B$ factors than the inner sugars (subsites -1 and -2 ). The inner sugars (subsites -1 and -2 ) have a chair conformation and the doublebonded sugars $(\Delta \mathrm{M})$ at the nonreducing ends (subsite -3 ) have an envelope conformation. It is interesting that the sugars at subsite +1 have a conformation that is slightly distorted from the complete chair form, although their precise conformation should be determined in a higher resolution experiment. The sugar dihedral angles ( $\varphi$ and $\psi$ ) of both complexes between subsites +1 and -1 , subsites -1 and -2 , and subsites -2 and -3 as shown in Table 3 are in the stable region for mannuronate disaccharide (Braccini et al., 1999).

\subsection{Interactions between the closed lid loop and the substrate}

The present experiment clearly shows that the two mutants bind tetrasaccharide in a productive manner by covering the catalytic site of the enzyme. The positions of the three sugar residues (subsites -1 to -3 ) are almost the same as those in the previous complex of the wild-type enzyme with a trisaccharide product in an open-lid conformation (Yoon et al., 2001). Several residues on the closed lid loop interact with the sugar at subsite -1 and also with the sugar at subsite +1 , as shown in Fig. 4 and Table 4. The side chains of Arg67, Tyr80 and Arg88 make four hydrogen bonds to mannuronate at subsite -1 (Table 4 ). These residues are buried in the closed lid loop (Fig. 3b).

Among these residues, the side chain of Arg88 located near the C-terminus of the lid loop moves about $5.5 \AA$ to interact with the sugar at subsite -1 , independently of the lid-loop motion (Fig. 3a). The interactions of the bound sugars and protein residues are almost the same in H192A and Y246F, except at subsite -2 (Fig. 3b). Both mannuronate (Y246F) and guluronate $(\mathrm{H} 192 \mathrm{~A})$ can bind at subsite -2 by forming three

Table 3

\section{Table 4}

$B$ factors and sugar-pucker parameters for bound tetrasaccharide.

The dihedral angles are defined as $\varphi, \mathrm{O} 5-\mathrm{C} 1-\mathrm{O}^{\prime}-\mathrm{C}^{\prime}$, and $\psi, \mathrm{C} 1-\mathrm{O}^{\prime}-\mathrm{C}^{\prime}-\mathrm{C}^{\prime}$.

\begin{tabular}{|c|c|c|c|c|c|c|c|c|c|c|}
\hline Site & Residue & Mutant & $B\left(\AA^{2}\right)$ & $\varphi\left(^{\circ}\right)$ & $\theta\left(^{\circ}\right)$ & $Q(\AA)$ & Form & Anomer & $\varphi\left({ }^{\circ}\right)$ & $\psi\left({ }^{\circ}\right)$ \\
\hline+1 & M & H192A & 48.0 & 95.4 & 15.7 & 0.551 & Near ${ }^{4} C_{1}$ & $\beta$ & & \\
\hline \multirow[t]{2}{*}{+1} & M & $\mathrm{Y} 246 \mathrm{~F}$ & 39.3 & 91.6 & 15.9 & 0.553 & Near ${ }^{4} C_{1}$ & $\beta$ & & \\
\hline & & $\begin{array}{l}\mathrm{H} 192 \mathrm{~A} \\
\text { Y246F }\end{array}$ & & & & & & & $\begin{array}{l}-19.0 \\
-623\end{array}$ & $\begin{array}{l}-175 \\
-139\end{array}$ \\
\hline-1 & $\mathrm{M}$ & H192A & 19.1 & 117 & 4.27 & 0.593 & ${ }^{4} C_{1}$ & $\beta$ & & \\
\hline \multirow[t]{2}{*}{-1} & M & Y246F & 27.5 & 132 & 6.64 & 0.583 & ${ }^{4} C_{1}$ & $\beta$ & & \\
\hline & & $\begin{array}{l}\text { H192A } \\
\text { Y246F }\end{array}$ & & & & & & & $\begin{array}{l}-75.3 \\
-64.8\end{array}$ & $\begin{array}{l}-91.0 \\
-103\end{array}$ \\
\hline-2 & G & H192A & 29.2 & 336 & 177 & 0.600 & ${ }^{1} C_{4}$ & $\alpha$ & & \\
\hline \multirow[t]{2}{*}{-2} & $\mathrm{M}$ & $\mathrm{Y} 246 \mathrm{~F}$ & 33.9 & 177 & 4.59 & 0.596 & ${ }^{4} C_{1}$ & $\beta$ & & \\
\hline & & $\begin{array}{l}\mathrm{H} 192 \mathrm{~A} \\
\mathrm{Y} 246 \mathrm{~F}\end{array}$ & & & & & & & $\begin{array}{l}-50.4 \\
-59.6\end{array}$ & $\begin{array}{l}-117 \\
-104\end{array}$ \\
\hline-3 & $\Delta \mathrm{M}$ & H192A & 45.5 & 118 & 54.4 & 0.505 & ${ }^{2} E$ & $\beta$ & & \\
\hline-3 & $\Delta \mathrm{M}$ & $\mathrm{Y} 246 \mathrm{~F}$ & 41.5 & 122 & 55.0 & 0.491 & ${ }^{2} E$ & $\beta$ & & \\
\hline
\end{tabular}

Interactions between bound sugar atoms and protein atoms (molecule $A$ ).

The residues in the lid loop are shown in bold.

\begin{tabular}{|c|c|c|c|c|}
\hline \multirow[b]{2}{*}{ Sugar atom } & \multirow[b]{2}{*}{ Protein atom } & \multicolumn{2}{|c|}{ Hydrogen-bond distance $(\AA)$} & \multirow[b]{2}{*}{ C. . C contacts less than $4.4 \AA$} \\
\hline & & H192A & $\mathrm{Y} 246 \mathrm{~F}$ & \\
\hline \multicolumn{5}{|l|}{ Site $-3, \Delta \mathrm{M}$} \\
\hline O61 & Gly313 N & 2.8 & 2.9 & $\operatorname{Arg} 312$ \\
\hline \multicolumn{5}{|l|}{ Site $-2, \mathrm{G}$} \\
\hline $\mathrm{O} 2$ & $\operatorname{Arg} 342 \mathrm{~N}^{\eta 1}$ & 2.9 & & $\operatorname{Arg} 306$ \\
\hline O3 $\cdots$ Wat $1 \cdots$ & Asp314 $\mathrm{O}^{\delta 2}$ & $2.8,2.6$ & & \\
\hline O61 & $\operatorname{Arg} 312 \mathrm{~N}^{\eta 2}$ & 2.6 & & \\
\hline O61 & $\operatorname{Arg} 306 \mathrm{~N}^{\eta 2}$ & 2.9 & & \\
\hline \multicolumn{5}{|l|}{ Site $-2, \mathrm{M}$} \\
\hline $\mathrm{O} 2 \ldots$ Wat $1 \cdots$ & Asp314 $\mathrm{O}^{\delta 2}$ & & $3.0,2.6$ & Arg306, Arg88 \\
\hline O62 & $\operatorname{Arg} 312 \mathrm{~N}^{\eta 2}$ & & 2.7 & \\
\hline O62 & $\operatorname{Arg} 306 \mathrm{~N}^{\eta 1}$ & & 2.7 & \\
\hline \multicolumn{5}{|l|}{ Site $-1, \mathrm{M}$} \\
\hline $\mathrm{O} 2$ & $\operatorname{Arg} 67 \mathrm{~N}^{\eta 1}$ & 3.2 & 3.3 & Arg67, Tyr80, Trp141 \\
\hline $\mathrm{O} 2$ & Tyr246 $\mathrm{O}^{\eta}$ & 3.2 & & Tyr246, Tyr249 \\
\hline $\mathrm{O} 3$ & His $245 \mathrm{~N}^{\varepsilon 2}$ & 3.1 & 3.2 & \\
\hline $\mathrm{O} 3$ & $\operatorname{Arg} 306 \mathrm{~N}^{\eta 2}$ & 3.6 & 3.4 & \\
\hline O3 $\cdots$ Wat $1 \cdots$ & Asp314 $\mathrm{O}^{\delta 2}$ & $2.6,2.6$ & $2.6,2.6$ & \\
\hline O61 & $\operatorname{Arg} 88 \mathrm{~N}^{\eta 2}$ & 3.1 & 3.2 & \\
\hline O61 & $\operatorname{Arg} 342 \mathrm{~N}^{\eta 1}$ & 2.9 & 2.9 & \\
\hline 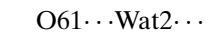 & $\mathrm{Gln} 138 \mathrm{O}^{\varepsilon 1}$ & $2.9,2.8$ & $2.8,3.0$ & \\
\hline O61 ...Wat $2 \cdots$ & $\operatorname{Arg} 342 \mathrm{~N}^{\eta 2}$ & $2.9,2.7$ & $2.8,2.8$ & \\
\hline O62 & Tyr80 $\mathrm{O}^{\eta}$ & 2.5 & 2.4 & \\
\hline O62 & $\operatorname{Arg67} N^{\varepsilon}$ & 2.9 & 3.1 & \\
\hline O62 & $\operatorname{Arg} 88 \mathrm{~N}^{\eta 2}$ & 3.3 & 3.2 & \\
\hline \multicolumn{5}{|l|}{ Site $+1 \mathrm{M}$} \\
\hline $\mathrm{O} 2$ & His192 $\mathrm{N}^{\varepsilon 2}$ & - & 3.2 & Arg67, Tyr68, Gln134 \\
\hline $\mathrm{O} 2$ & $\mathrm{G} \ln 134 \mathrm{O}^{\varepsilon 1}$ & 3.2 & 3.3 & \\
\hline $\mathrm{O} 3$ & $\mathrm{Gln} 134 \mathrm{~N}^{\varepsilon 2}$ & 3.2 & 3.2 & Tyr137, Trp141, Asn191 \\
\hline $\mathrm{O} 4$ & Tyr246 $\mathrm{O}^{\eta}$ & 3.0 & - & Tyr246 \\
\hline O5 & His $192 \mathrm{~N}^{\varepsilon 2}$ & - & 2.9 & \\
\hline O61 & Asn191 O $\mathrm{O}^{\delta 1}$ & 3.1 & 2.9 & \\
\hline O61 & $\operatorname{Arg} 239 \mathrm{~N}^{\eta 1}$ & 2.9 & 3.1 & \\
\hline O62 & Asn191 N ${ }^{\delta 2}$ & 3.1 & 2.8 & \\
\hline
\end{tabular}

and four hydrogen bonds, respectively, each including one water-mediated hydrogen bond (Table 4).

\subsection{Catalytic mechanism of A1-III}

Comparison of the structures of holo H192A and holo Y246F provided an important clue to the mechanism of this 


\section{research papers}

enzyme. In the H192A holo structure, Tyr246 $\mathrm{O}^{\eta}$ makes two hydrogen bonds to $\mathrm{O} 4$ of mannuronate at subsite +1 and $\mathrm{O} 2$ of mannuronate at subsite -1 . The distance between Tyr246 $\mathrm{O}^{\eta}$ and C5 of mannuronate at subsite +1 is only $3.3 \AA$, suggesting that Tyr246 can extract a hydrogen from the C5 atom (Fig. 5). In contrast, the side chain of His 192 in holo Y246F is situated at the other side of Tyr246 and makes two hydrogen bonds to $\mathrm{O} 2$ and $\mathrm{O} 5$ of mannuronate at subsite +1 , with the distance between His192 $\mathrm{N}^{\varepsilon 2}$ and $\mathrm{C} 5$ of mannuronate at subsite +1

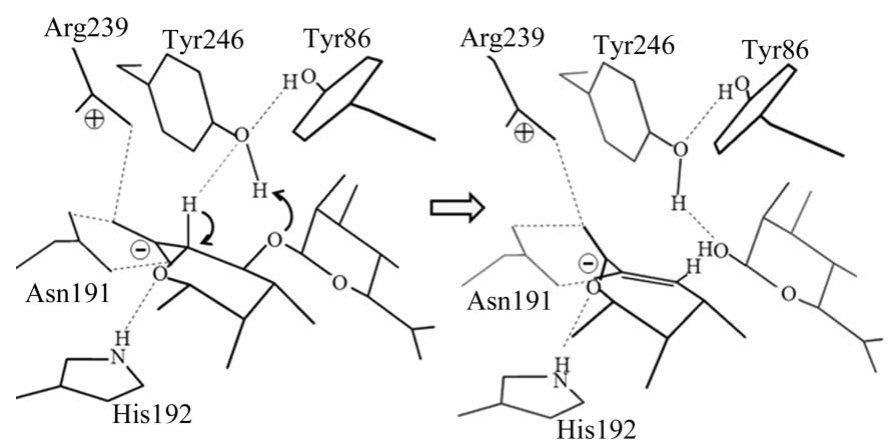

Figure 5

Schematic representation of the catalytic mechanism of alginate lyase A1III. The side chain of Tyr246 is responsible for simultaneous abstraction and donation of hydrogen without side-chain conformational change. The side chain of Tyr68 in the closed lid loop forms a hydrogen bond to the side chain of Tyr246 that accelerates proton transfer. being $3.4 \AA$ (Figs. 1 and $3 c$ ). The mannuronate at subsite +1 in both holo structures has a near-chair form (Table 3 ), with the $\mathrm{H}$ atom of $\mathrm{C} 5$ facing towards the side chain of Tyr246. It is suggested from the distance between Tyr246 $\mathrm{O}^{\eta}$ and $\mathrm{O} 4$ of mannuronate at subsite $+1(2.9 \AA)$ that Tyr246 $\mathrm{O}^{\eta}$ can also donate a hydrogen to $\mathrm{O} 4$ of the glycoside bond to be cleaved. The $\mathrm{C}^{\zeta} \ldots \mathrm{O}^{\eta} \ldots \mathrm{C} 5$ and $\mathrm{C}^{\zeta} \ldots \mathrm{O}^{\eta} \ldots \mathrm{O} 4$ angles are $103^{\circ}$ and $109^{\circ}$, respectively (Fig. $3 c$ ), suggesting that the reaction coordinates are almost the same for abstraction and donation. Thus, in this lyase reaction without conformational change of the side chain, the side chain of Tyr246 is responsible for both the abstraction and donation of hydrogen simultaneously, as shown in the schematic view in Fig. 5. Several positively charged side chains, Arg239 (3.5 $\AA$ from Tyr246 O ${ }^{\eta}$ ), Arg67 (4.8 $\mathrm{\AA}), \operatorname{Arg} 306(6.1 \AA)$, His245 (5.4 $\mathrm{\AA})$ and His192 (6.4 $\mathrm{\AA})$, surrounding Tyr $246 \mathrm{O}^{\eta}$ may reduce the $\mathrm{p} K_{\mathrm{a}}$ of $\operatorname{Tyr} 246$ and facilitate the abstraction and donation of $\mathrm{H}$ atoms. For abstraction of the $\mathrm{H}$ atom to occur, the sugar ring must be distorted with a coplanar $\mathrm{C} 3-\mathrm{C} 4-\mathrm{C} 5-\mathrm{O} 5$ configuration similar to the product double-bonded sugar. The slightly distorted sugar rings of subsite +1 in both mutant structures suggest that some additional residues other than Tyr246 and His192 may be responsible for distortion of the sugar ring at subsite +1 . These residues are estimated to be Asn191 and Arg239 based on their interaction with mannuronate at subsite +1 . The side-chain atoms of Asn191 and Arg239 are

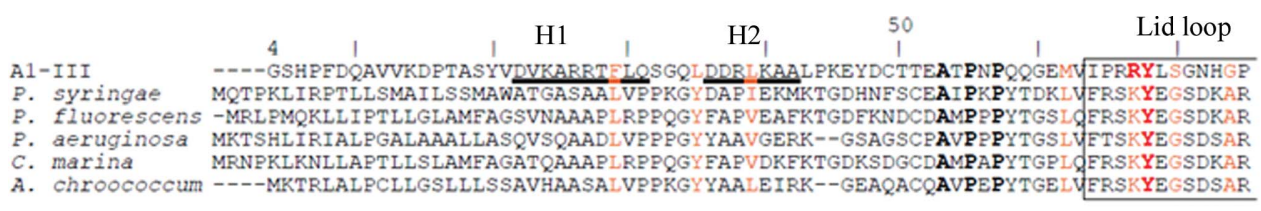

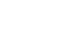

A1-II

H3

100

$\mathrm{H} 4$

$\mathrm{H} 5$

P. SYringae VNPDYEPVVTL RDFEKISAT G------NL YVATG PVXATCLLNMI DKWAKADALLNYD PKSOSWXOVEWSAATZ

P. fluorescens STLNVQSEKA--FRDSTADITKLEKDTSKRVMQEMRDGRPEQLECTLNWLTSWAKADALMSKDFNHTGKSMRKWALGSM

P. aeruginosa ATLNVKAEKT-ERSQIKDITDMERGATKLVTQYMRSGRDGDLACALNWMSAWARAGALQSDD FNHTGKSMRKWALGSL

C. marina ATLNVQSEKA-ERDTTKDITTLERGTAKRVMQEMRDGREQLECTLNWLTAWAKADALMSKDFNHTGKSMRKWALGSM

A. chroococcum STLNKKAEKA-FRAKTKPITEIERGVSRMVMRYMEKGRLRRAGMRPGLIDAWAEDDALLSTEYNHTGKSMRKWALGSL

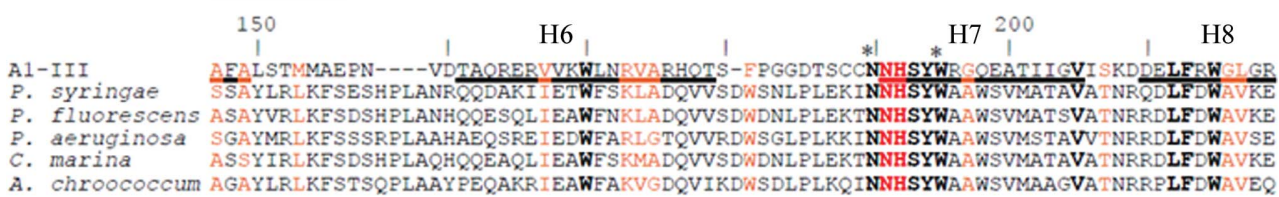

H9 250

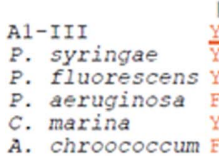

VOAMGLINEDGSFVHEMTRH

VQAMGLINEDGSFVHEMTRH

VAANOVDKDGELPNEMKRR RT LHYONY

1

1

1
1

KENGR

H10

YYHNY P PLAMIASEA QANG DLRP --ENNGA IRLGDRVLA VKD PS

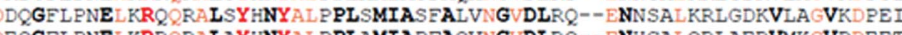

C. mering

A. chroococcum FHIAAKQVDPRGLANE KRRQRALAYHNY SLPLMMIAARQANG DLRG--D NGALGRLAGNVLAGVEPEP

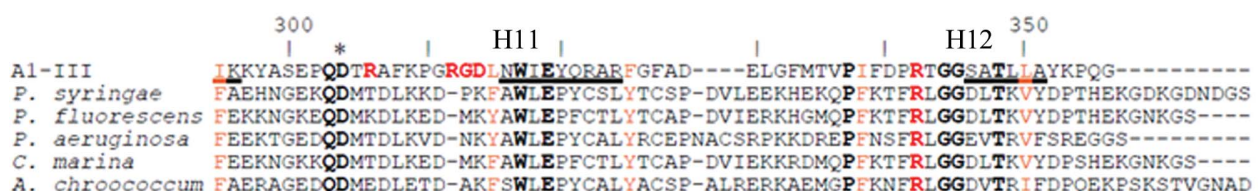

A. Chroococcum FAERAGEDODMEDLETD-AKESWLEPYCALYACSP-ALRERKAEMGP KNERLGGDVTRIFDPQEKPSKSTVGNAD

\section{Figure 6}

Multiple sequence alignment of mannuronate-specific alginate lyases belonging to the PL-5 family. The position of the lid loop in A1-III is boxed. Identical residues are shown in bold. The A1-III residues involved in interaction with the substrate are labelled in red. Conserved residues are labelled in orange. The helices in A1-III are underlined. The conserved amino-acid residues in the active site of A1-III that are not involved in direct interaction with substrate are marked by asterisks. near $\mathrm{O} 6$ and $\mathrm{O} 5$ of mannuronate at subsite +1 , respectively (Fig. $3 c$ and Table 4). These side chains collaborate with His192 to distort the sugar ring and assist in the catalysis conducted by the side chain of Tyr246. These residues have also been shown to be important in chondroitin AC lyase (PL-8; Lunin et al., 2004; Huang et al., 2001), hyaluronate lyase (Li \& Jedrzejas, 2001; Mello et al., 2002; Nukui et al., 2003; Rigden \& Jedrzejas, 2003) and xanthan lyase (Maruyama et al., 2005, 2007).

The present experiment also showed the important role of the lid loop in the activation of Tyr246. The side chain of Tyr68 in the closed lid loop makes a hydrogen bond to the side chain of Tyr246 (Tyr68 O ${ }^{\eta} \ldots$ Tyr246 O ${ }^{\eta}$, $2.6 \AA$ ) and is near the positively charged side chain of Arg67 $\left(\operatorname{Tyr} 68 \mathrm{O}^{\eta} \cdots \operatorname{Arg} 67 \mathrm{~N}^{\eta 1}, \quad 3.3 \AA\right.$ ) (Figs. $3 c$ and 4 ). We speculate that when Tyr68 $\mathrm{O}^{\eta}$ donates its hydrogen to Tyr246 $\mathrm{O}^{\eta}$ to make the hydrogen bond, the $\mathrm{p} K_{\mathrm{a}}$ value of Tyr246 decreases by stabilizing 
the deprotonated form, thereby accelerating proton transfer. The results for the mutation of Tyr68 to Phe68 (Table 1) showed that the side chain of Tyr68 accelerates catalysis by about 20 -fold, which is consistent with this hypothesis.

\subsection{Sequence comparison of PL-5 alginate lyase}

Fig. 6 shows a sequence alignment of mannuronate-specific lyases in PL-5. The sequence around Tyr246 and His192 of A1-III is strongly conserved in the six sequences from various microorganisms. Although the sequence similarity in the lid loop region is not as high as the similarity in the regions of Tyr246 and His192, Tyr68 and Arg88 are well conserved. The position of Arg67 in A1-III is conserved as an Arg or a Lys residue. This conservative replacement is also found for Asn72 (Asp), Gly74 (Ala), Asp79 (Asn) and Tyr87 (Phe). These results suggest that the mobile lid loop of A1-III is functional throughout the family of PL-5 mannuronate-specific alginate lyases.

\section{Conclusion}

The crystal structures of alginate lyase mutants (Y246F and H192A) complexed with alginate tetrasaccharide have been explored in this study. The lid loop (residues 64-85) of alginate lyase A1-III can move with a maximum distance of $13.4 \AA$ from the open form (apoenzyme) to the closed form (holoenzyme) in the orthorhombic crystal system. The conformational change of this loop is a near-rigid-body motion with hinges around residues 64 and $82-85$. The conformational change is larger than the usual loop motion of the $\omega$ loop, as the lid loop contains a longer loop and part of the $\alpha$-helix (H3) region. The closed lid loop interacts with the bound tetrasaccharide and a catalytic residue. In particular, Tyr68 in the closed lid loop was expected to activate a presumed catalytic residue, Tyr246, by forming a hydrogen bond. From alignment of primary structures of PL-5 mannuronate-specific alginate lyases, the lid loop seems to be conserved in this family of enzymes. The tetrasaccharide formed a bond in the active cleft at subsites -3 to +1 as a substrate form in which the glycosidic linkage to be cleaved is present between subsites -1 and +1 . Based on the configuration of Tyr246 towards the substrate sugar, it is concluded that the side chain of Tyr246 acts as both an acid and a base catalyst in a syn mechanism.

Diffraction data for Y246F were collected at the BL-38B1 station of SPring-8 (Hyogo, Japan) with the approval of JASRI (Proposal No. C99A24XU-003N). Computation time was provided by the Supercomputer Laboratory, Institute for Chemical Research, Kyoto University, Japan. This work was supported in part by a Grant-in-Aid for Scientific Research from the Ministry of Education, Science, Sports and Culture of Japan and by Research Fellowships from the Japan Society for the Target Protein Project. Part of this work was also supported by the Program of Basic Research Activities for Innovative Biosciences (PROBRAIN) of Japan.

\section{References}

Adams, P. D. et al. (2010). Acta Cryst. D66, 213-221.

Boyd, A., Ghosh, M., May, T. B., Shinabarger, D., Keogh, R. \& Chakrabarty, A. M. (1993). Gene, 131, 1-8.

Braccini, I., Grasso, R. P. \& Pérez, S. (1999). Carbohydr. Res. 317, 119-130.

Brünger, A. T., Adams, P. D., Clore, G. M., DeLano, W. L., Gros, P., Grosse-Kunstleve, R. W., Jiang, J.-S., Kuszewski, J., Nilges, M., Pannu, N. S., Read, R. J., Rice, L. M., Simonson, T. \& Warren, G. L. (1998). Acta Cryst. D54, 905-921.

Cantarel, B. L., Coutinho, P. M., Rancurel, C., Bernard, T., Lombard, V. \& Henrissat, B. (2009). Nucleic Acids Res. 37, D233-D238.

Cremer, D. \& Pople, J. A. (1975). J. Am. Chem. Soc. 97, 1354-1358.

Davies, G. J., Wilson, K. S. \& Henrissat, B. (1997). Biochem. J. 321, 557-559.

Dunlop, K. V., Irvin, R. T. \& Hazes, B. (2005). Acta Cryst. D61, 80-87.

Elmabrouk, Z. H., Vincent, F., Zhang, M., Smith, N. L., Turkenburg, J. P., Charnock, S. J., Black, G. W. \& Taylor, E. J. (2011). Proteins, 79, 965-974.

Emsley, P., Lohkamp, B., Scott, W. G. \& Cowtan, K. (2010). Acta Cryst. D66, 486-501.

Féthière, J., Eggimann, B. \& Cygler, M. (1999). J. Mol. Biol. 288, 635-647.

Garron, M. L. \& Cygler, M. (2010). Glycobiology, 20, 1547-1573.

Gerstein, M. \& Krebs, W. (1998). Nucleic Acids Res. 26, 4280-4290.

Gimmestad, M., Sletta, H., Ertesvåg, H., Bakkevig, K., Jain, S., Suh, S., Skjåk-Braek, G., Ellingsen, T. E., Ohman, D. E. \& Valla, S. (2003). J. Bacteriol. 185, 3515-3523.

Hooft, R. W., Vriend, G., Sander, C. \& Abola, E. E. (1996). Nature (London), 381, 272.

Huang, W., Boju, L., Tkalec, L., Su, H., Yang, H.-O., Gunay, N. S., Linhardt, R. J., Kim, Y. S., Matte, A. \& Cygler, M. (2001). Biochemistry, 40, 2359-2372.

Hubbard, S. J. \& Thornton, J. M. (1993). NACCESS. Department of Biochemistry and Molecular Biology, University College, London.

Jedrzejas, M. J., Mello, L. V., de Groot, B. L. \& Li, S. (2002). J. Biol. Chem. 277, 28287-28297.

Laskowski, R. A., MacArthur, M. W., Moss, D. S. \& Thornton, J. M. (1993). J. Appl. Cryst. 26, 283-291.

Li, S. \& Jedrzejas, M. J. (2001). J. Biol. Chem. 276, 41407-41416.

Li, S., Taylor, K. B., Kelly, S. J. \& Jedrzejas, M. J. (2001). J. Biol. Chem. 276, 15125-15130.

Lombard, V., Bernard, T., Rancurel, C., Brumer, H., Coutinho, P. M. \& Henrissat, B. (2010). Biochem J. 432, 437-444.

Lunin, V. V., Li, Y., Linhardt, R. J., Miyazono, H., Kyogashima, M., Kaneko, T., Bell, A. W. \& Cygler, M. (2004). J. Mol. Biol. 337, 367-386.

Luzzati, V. (1952). Acta Cryst. 5, 802-810.

Maruyama, Y., Hashimoto, W., Mikami, B. \& Murata, K. (2005). J. Mol. Biol. 350, 974-986.

Maruyama, Y., Mikami, B., Hashimoto, W. \& Murata, K. (2007). Biochemistry, 46, 781-791.

Mello, L. V., De Groot, B. L., Li, S. \& Jedrzejas, M. J. (2002). J. Biol. Chem. 277, 36678-36688.

Murata, K., Inose, T., Hisano, T., Abe, S., Yonemoto, Y., Yamashita, T., Takagi, M., Sakaguchi, K., Kimura, A. \& Imanaka, T. (1993). J. Ferment. Bioeng. 76, 427-437.

Noble, M. E. M., Zeelen, J. P. \& Wierenga, R. K. (1993). Proteins, 16, 311-326.

Nukui, M., Taylor, K. B., McPherson, D. T., Shigenaga, M. K. \& Jedrzejas, M. J. (2003). J. Biol. Chem. 278, 3079-3088.

Ochiai, A., Yamasaki, M., Mikami, B., Hashimoto, W. \& Murata, K. (2010). J. Biol. Chem. 285, 24519-24528.

Ogura, K., Yamasaki, M., Mikami, B., Hashimoto, W. \& Murata, K. (2008). J. Mol. Biol. 380, 373-385.

Osawa, T., Matsubara, Y., Muramatsu, T., Kimura, M. \& Kakuta, Y. (2005). J. Mol. Biol. 345, 1111-1118. 


\section{research papers}

Otwinowski, Z. \& Minor, W. (1997). Methods Enzymol. 276, 307326.

Peciña, A., Pascual, A. \& Paneque, A. (1999). J. Bacteriol. 181, 1409 1414.

Ponnuraj, K. \& Jedrzejas, M. J. (2000). J. Mol. Biol. 299, 885-895.

Preston, L. A., Wong, T. Y., Bender, C. L. \& Schiller, N. L. (2000). J. Bacteriol. 182, 6268-6271.

Ramachandran, G. N. \& Sasisekharan, V. (1968). Adv. Protein Chem. 23, 283-438.

Rigden, D. J., Botzki, A., Nukui, M., Mewbourne, R. B., Lamani, E., Braun, S., von Angerer, E., Bernhardt, G., Dove, S., Buschauer, A. \& Jedrzejas, M. J. (2006). Glycobiology, 16, 757-765.

Rigden, D. J. \& Jedrzejas, M. J. (2003). J. Biol. Chem. 278, 5059650606.

Shaya, D., Zhao, W., Garron, M. L., Xiao, Z., Cui, Q., Zhang, Z., Sulea, T., Linhardt, R. J. \& Cygler, M. (2010). J. Biol. Chem. 285, 20051-20061.

Skrzypczak-Jankun, E., Borbulevych, O. Y., Zavodszky, M. I., Baranski, M. R., Padmanabhan, K., Petricek, V. \& Jankun, J.
(2006). Acta Cryst. D62, 766-775.

Spek, A. L. (2003). J. Appl. Cryst. 36, 7-13.

Thompson, J. D., Higgins, D. G. \& Gibson, T. J. (1994). Nucleic Acids Res. 22, 4673-4680.

Tsitsanou, K. E., Oikonomakos, N. G., Zographos, S. E., Skamnaki, V. T., Gregoriou, M., Watson, K. A., Johnson, L. N. \& Fleet, G. W. (1999). Protein Sci. 8, 741-749.

Winn, M. D. et al. (2011). Acta Cryst. D67, 235-242.

Yamasaki, M., Ogura, K., Hashimoto, W., Mikami, B. \& Murata, K. (2005). J. Mol. Biol. 352, 11-21.

Yonemoto, Y., Tanaka, H., Hisano, T., Sakaguchi, K., Abe, S., Yamashita, T., Kimura, A. \& Murata, K. (1993). J. Ferment. Bioeng. 75, 336-342.

Yoon, H.-J., Hashimoto, W., Miyake, O., Murata, K. \& Mikami, B. (2001). J. Mol. Biol. 307, 9-16.

Yoon, H.-J., Hashimoto, W., Miyake, O., Okamoto, M., Mikami, B. \& Murata, K. (2000). Protein Expr. Purif. 19, 84-90.

Yoon, H.-J., Mikami, B., Hashimoto, W. \& Murata, K. (1999). J. Mol. Biol. 290, 505-514. 